\title{
Pengembangan Model Blended Web Mobile Learning dengan Aplikasi MoLearn untuk Meningkatkan Keterampilan Berpikir Tingkat Tinggi Siswa SMA
}

\author{
${ }^{1 a \star}$ Bambang Hariadi, ${ }^{2 b}$ MJ Dewiyani Sunarto, ${ }^{2 b}$ Tri Sagirani, ${ }^{2 b}$ Tan Amelia, ${ }^{2 b}$ Julianto \\ Lemantara, ${ }^{3}$ Binar Kurnia Prahani, ${ }^{3}$ Budi Jatmiko \\ 1aprogram Studi Produksi Film dan Televisi, FDIK; ${ }^{2 b}$ Program Studi Sistem Informasi, FTI \\ Universitas Dinamika, Jl. Raya Kedung Baruk 98 Surabaya 60298, Indonesia. \\ ${ }^{3}$ Program Studi Pendidikan Fisika, FMIPA, Universitas Negeri Surabaya, Jl. Ketintang, \\ Surabaya 60231, Indonesia
}

*Email Korespondensi: bambang@dinamika.ac.id

\begin{abstract}
Abstrak
Penelitian ini bertujuan untuk meningkatkan hasil belajar siswa SMA berbasis Higher Order Thinking Skill (HOTS) melalui pembudayaan belajar dengan pendekatan blended learning dengan menerapkan model Blended Web Mobile Learning (BWML) dan aplikasi MoLearn. Penelitian ini merupakan penelitian pengembangan yang mengacu pada Generic Design Research Model (GDRM) dari Plomp dan Nieveen. Untuk pengembangan aplikasi MoLearn metode System Development Life Cycle (SDLC) model waterfall digunakan dalam penelitian ini. Penelitian ini meibatkan 205 siswa sebagai subjek penelitiaan. Data penelitian dikumpulkan menggunakan instrument lembar validasi model, angket resposn siswa, dan tes HOTs siswa. Penelitian dianalisis secara deskriptif menggunakan persamaan reliabilitas dan n-gain. Hasil penelitian menunjukkan bahwa (1) model BWML dengan aplikasi MoLearn dinyatakan valid dan reliable berdasarkan tinjauan content dan isi, selain itu, berdasarkan hasil respon 205 siswa terhadap pembelajaran model BWML dengan aplikasi MoLearn, 83\% siswa dinyatakan antusias mengikuti pembelajaran; dan (2) peningkatan HOTs siswa dinyatakan meningkat (rerata $n$-gain= 0,46 ) dengan kategori sedang. Hasil penelitian ini menyimpulkan bahwa model Blended Web Mobile Learning (BWML) dengan aplikasi MoLearn valid, praktis, dan efektif untuk meningkatkan keterampilan berpikir tingkat tinggi siswa SMA.
\end{abstract}

Kata kunci: blended web mobile learning, MoLearn, keterampilan berpikir tingkat tinggi

\section{The Development of the Blended Web Mobile Learning Model with the MoLearn Application to Improve High School Students' Higher Order Thinking Skills}

\begin{abstract}
This study aims to improve the learning outcomes of high school students based on Higher Order Thinking Skills (HOTS) through the culture of learning with a blended learning approach by applying the Blended Web Mobile Learning (BWML) model and the MoLearn application. This research is a development research that refers to the Generic Design Research Model (GDRM) from Plomp and Nieveen. For the development of the MoLearn application, the Waterfall Model System Development Life Cycle (SDLC) method was used in this study. This study involved 205 students as research subjects. The research data were collected using a model validation sheet instrument, student response questionnaires, and student HOTs tests. The research was analyzed descriptively using the reliability equation and $n$-gain. The results showed that (1) the BWML model with the MoLearn application was declared valid and reliable based on the content and content review, in addition, based on the results of the responses of 205 students to the BWML model learning with the MoLearn application, 83\% of the students were stated to be enthusiastic about participating in the learning; and (2) the increase in students' HOTs was stated to be increasing (mean n-gain $=0.46$ ) in the medium category. The results of this study conclude that the Blended Web Mobile Learning (BWML) model with the MoLearn application is valid, practical, and effective for improving high school students' higher order thinking skills.
\end{abstract}

Keywords: blended web mobile learning, MoLearn, higher order thinking skills

How to Cite: Hariadi, B., Sunarto, M. J. D., Sagirani, T., Amelia, T., Lemantara, J., Prahani, B. K., \& Jatmiko, B. (2021). Pengembangan Model Blended Web Mobile Learning dengan Aplikasi MoLearn untuk Meningkatkan Keterampilan Berpikir Tingkat Tinggi Siswa SMA. Empiricism Journal, 2(2), $63-72$. https://doi.org/10.36312/ej.v2i2.560 


\section{PENDAHULUAN}

Pembelajaran abad 21 dan di era revolusi industri 4.0 ini memerlukan SDM dengan standar kompetensi lulusan diarahkan pada higher order thinking skills (HOTS) dan inovasi pembelajaran, antara lain yaitu: keterampilan berpikir kritis, keterampilan pemecahan masalah, literasi, kolaborasi, pengambilan keputusan, berpikir kreatif, bertanggung jawab, dan mampu belajar secara mandiri (Jatmiko dkk., 2018; Pandiangan dkk., 2017; Prahani dkk., 2018; Sunarti dkk., 2018). Hasil belajar berbasis HOTS ini sangat penting karena menjadi bekal kompetensi siswa untuk bersaing dan unggul di era revolusi industri 4.0. Oleh karena itu, adanya urgensi hasil belajar berbasis HOTS ini harus benar-benar dikuatkan melalui model pembelajaran inovatif di Indonesia. Rendahnya hasil belajar siswa SMA berbasis HOTS diduga ada kaitannya dengan proses pembelajaran yang digunakan. Model pembelajaran yang digunakan, yaitu Model Pembelajaran Konvensional kurang dapat memfasilitasi pengembangan hasil belajar siswa SMA berbasis HOTS, sehingga dapat diduga sebagai penyebab rendahnya prestasi belajarnya (Prahani dkk., 2017; Wicaksono dkk., 2017).

Permasalahan penting terkait peningkatan kualitas proses dan hasil belajar siswa di era revolusi industri 4.0 adalah bagaimana mengupayakan peningkatan higher order thinking skills (HOTs) (Jatmiko dkk., 2018; Prahani dkk., 2018; Sunarti dkk., 2018; Suyidno dkk., 2018). Termasuk salah satu permasalahan tersebut adalah pada hasil belajar siswa SMA melalui pembelajaran inovatif yang mengintegrasikan web dan mobile learning menjadi pembelajaran yang efektif dan efesien.

Minimnya media yang berkaitan dengan materi pembelajaran juga menyebabkan pembelajaran menjadi monoton dan siswa kurang termotivasi untuk menerima dan memahami materi. Seharusnya pada pembelajaran diberikan inovasi belajar yang mampu mendongkrak peserta didik untuk turut aktif dan antusias dalam belajar. Penerapan media digital dalam pembelajaran sangat mempengaruhi aktivitas siswa dalam mengikuti pembelajaran di kelas (Umam, 2013).

Peningkatan jumlah dan ragam sumber belajar bermutu di sekolah menjadi kebutuhan yang harus dilaksanakan oleh sekolah. Perkembangan ilmu pengetahuan yang begitu cepat dalam era digital menuntut pembaharuan dan penambahan pengetahuan baru di lingkungan sekolah. Dalam hal ini, sekolah dituntut dapat meningkatkan jumlah dan ragam sumber belajar bermutu bagi warga sekolahnya, terutama untuk peserta didik. Beberapa hal yang bisa dilakukan oleh sekolah dalam peningkatan jumlah dan ragam sumber belajar bermutu terkait literasi digital di lingkungan sekolah (Nasrullah dkk., 2017).

Senada dengan Nasrullah dkk. (2017), Atsani (2020) mengemukanan bahwa pendidik dituntut agar mendesain media pembelajaran sebagai inovasi dengan memanfaatkan media daring (online). Sistem pembelajaran dilaksanakan melalui perangkat personal computer (PC) atau laptop yang terhubung dengan koneksi jaringan internet. Meski demikian, Atsani (2020) menyampaikan beberapa kelemahan pembelajaran online. Menurutnya, yang banyak terjadi ketika penerapan sistem pembelajaran online ini di antaranya adalah, tidak meratanya siswa dan orang tua siswa yang pandai mengoperasikan media online. Untuk mengatasi hal tersebut, perlu dirancang pembelajaran yang menggabungkan online learning dengan offline learning yang selanjutnya disebut blended learning.

Gagasan untuk menerapkan blanded learning pada pembelajaan di SMA diawali dengan penelitian yang telah menguji penerapan online learning pada pendidikan tinggi. Hasil penelitian tersebut menunjukkan adanya nilai positif dari pembelajaran berbasis web dan juga ada nilai positif pada pembelajaran konvensional yang selanjutnya memunculkan saran untuk menerapkan blanded learning (Hariadi, 2015; Hariadi dkk., 2016; Hariadi \& Wurijanto, 2016). Hasil-hasil penelitian tersebut selanjutnya dikembangkan untuk penerapan pada pembelajaran di SMA dengan membangun aplikasi mobile learning bagi siswa SMA yang diberi nama "MoLearn" (Sunarto dkk., 2017).

Model PBL dapat meningkatkan keterampilan belajar mandiri dan memberikan sebuah gambaran yang lebih realistis dari tantangan akademis yang lebih tinggi, dapat meningkatkan keterampilan penyelesaian masalah, keterampilan berpikir kritis, dan adanya peningkatan keterampilan komunikasi dan literasi (Arizaga dkk., 2016; Benade, 2018; Caesar dkk., 2016; Sunarti dkk., 2018). Namun, Model PBL masih lemah dalam hal komponen orientasi penyelidikan, alternatif solusi, mengalami kesulitan dalam merumuskan masalah dan menyusun hipotesis, kurang dalam memberikan inisiasi dan pengaturan waktu, lemah dalam 
melatihkan kedisiplinan siswa, dan masih diperlukan masalah autentik yang lebih menantang (Chakravarthi \& Haleagrahara, 2010; Sern dkk., 2015). Oleh karena itu, masih diperlukan perbaikan dan penyempurnaan model PBL untuk meningkatkan hasil belajar siswa SMA berbasis HOTs.

Model blanded learning adalah pembelajaran untuk menyediakan isi model pembelajaran dalam berbagai media (termasuk, namun tidak terbatas pada tradisional, berbasis web, berbasis komputer dan video teletraining) untuk mengikuti dengan kebutuhan belajar saat ini (Sunarto, 2021). Penerapan blanded learning ini dapat meningkatkan hasil belajar siswa SMA berbasis HOTs, namun masih perlu penyempurnaan dengan mengintegrasikan aplikasi yang dapat menyiapkan siswa SMA bersaing di era revolusi industri 4.0 yang ditandai dengan Internet of Things (IoTs) dan Big Data.

Model pembelajaran inovatif yang dikembangkan adalah Model Blended Web Mobile Learning (BWML). Model BWML merupakan model pembelajaran yang mengintegrasikan Model blanded learning dengan Model PBL yang didukung dengan penggunaan aplikasi MoLearn di setiap kegiatan pembelajaran. Model BWML memiliki lima fase, yaitu: (1) Orientasi berbasis loTs dan Big Data, (2) Investigasi, (3) Menganalisis, (4) Mempresentasikan, serta (5) Mengevaluasi yang mana di setiap fase dilaksanakan dan didukung dengan menggunakan aplikasi MoLearn.

Aplikasi MoLearn merupakan sebuah aplikasi untuk blanded learning yang telah dikembangkan oleh tim peneliti Universitas Dinamika dengan tujuan untuk meningkatkan hasil belajar berbasis HOTS bagi siswa SMA. Aplikasi pembelajaran 'MoLearn' yang dihasilkan dapat dikelompokkan menjadi dua yaitu (1) versi web dan (2) versi android. Aplikasi MoLearn ini adalah aplikasi pembelajaran blanded learning yaitu aplikasi yang bisa digunakan untuk pembelajaran tatap muka (dengan guru) dan juga untuk pembelajaran mandiri tanpa guru. Dengan menggunakan konsep blanded learning, maka pembelajaran tidak hanya dilaksanakan di dalam kelas, tetapi juga dilaksanakan di dunia maya. Berdasarkan uraian tersebut, penelitian ini bertujuan untuk mengembangkan model blended web mobile learning didukung aplikasi MoLearn untuk meningkatkan keterampilan berpikir tingkat tinggi siswa SMA.

\section{METODE}

Dalam mencapai tujuan penelitian yang telah diuraikan sebelumnya, secara umum penelitian ini dilaksanakan dalam tiga langkah, yaitu (1) mengembangkan model pembelajaran yang sesuai, (2) mengembangkan aplikasi untuk penerapan model pembelajaran yang telah dikembangkan dan (3) melakukan uji coba dan menilai hasil belajar untuk mengukur keefektifan. Berikut diuraikan langkah-langkah yang dimaksud.

\section{Pengembangan Model}

Pengembangan Model BWML mengacu pada desain model penelitian pengembangan Generic Design Research Model menurut Wademan. Langkah pengembangan GDRM (Nieveen, 1999; Plomp, 2013) adalah 1) identifikasi masalah, 2) identifikasi prinsip-prinsip produk dan desain secara tentatif, 3) teori dan produk secara tentatif, 4) membuat prototipe dan menilai produk, dan 5) meningkatkan kualitas produk. Penilaian kualitas produk dilakukan melalui implementasi dalam pembelajaran di kelas. Implementasi produk dilakukan melalui uji coba keterlaksaaan model, uji coba terbatas, dan uji coba luas. Uji coba keterlakasanaan model diperoleh data keterlaksanaan (data kualitatif keterlaksanaan), pada uji coba terbatas maupun uji coba luas maka dapat dievaluasi kualitas produk ditinjau dari kepraktisan dan keefektifannya. Tahap pengembangan model pembelajaran hipotetik dengan memodifikasi generic design research model (Plomp, 2013) sebagaimana Gambar 1 berikut. 


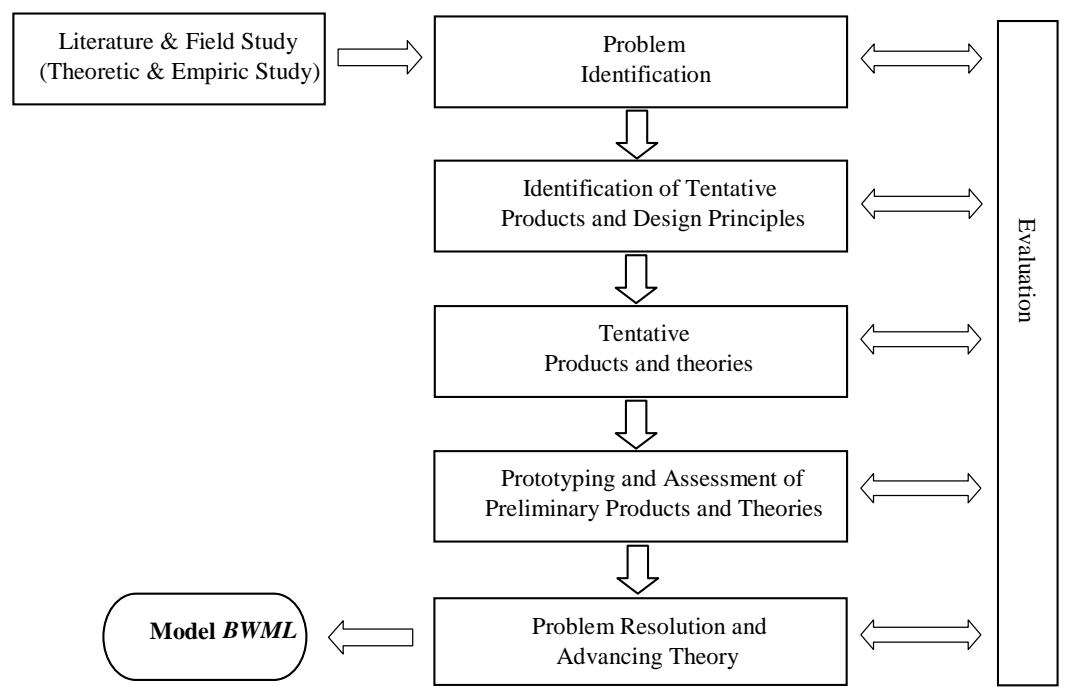

Gambar 1. Tahapan pengembangan model BWML

\section{Pengembangan Aplikasi}

Dalam pengembangan aplikasi MoLearn, penelitian ini menggunakan metode System Development Life Cycle (SDLC) model waterfall. Adapun tahapan SDLC yang dilakukan meliputi (1) Requirement Analysis (Analisis Kebutuhan), yaitu tahapan untuk mencari kebutuhan data, kebutuhan pengguna, kebutuhan fungsional dan nonfungsional dari aplikasi; (2) Design (Desain), yaitu tahapan untuk merancang sistem, mulai dari merancang basis data, antarmuka pengguna, dan desain input/output; (3) Development (Pengembangan/Konstruksi), yaitu tahapan membuat aplikasi. Dalam hal ini, aplikasi yang dibuat adalah penilaian respon soal essay secara otomatis dengan GLSA. Tahapan GLSA meliputi: pembuatan dokumen matriks, decompose dokumen matriks menggunakan SVD, reduksi dimensi, hitung vektor, dan hitung kesamaan semantik dengan cosine similarity; (4) Testing (Pengujian), yaitu tahapan menguji aplikasi yang dibuat sehingga kekurangan aplikasi dapat ditemukan dan diperbaiki; dan (5) Maintenance (Pemeliharaan), yaitu tahapan untuk melakukan implementasi dan memelihara aplikasi apabila ada perbaikan di kemudian hari.

\section{Pengukuran Hasil Belajar}

Desain penelitian ini menggunakan pre-test and post-test control group design (Fraenkel dkk., 2012).

Keterangan:

$$
\begin{array}{lll}
\mathrm{O}_{1} & \mathrm{X} & \mathrm{O}_{2} \\
\mathrm{O}_{1} & \mathrm{C} & \mathrm{O}_{2}
\end{array}
$$

$\mathrm{O}_{1}$ : Pre-test,

$\mathrm{O}_{2}$ : Post-test,

$\mathrm{X}$ : Aplikasi MoLearn Terintegrasi Model BWML;

C: Model K 13

Implementasi aplikasi MoLearn terintegrasi Model BWML yang melibatkan dua kelas yang masing-masing dipilih dengan teknik purposive sampling. Penelitian diawali dengan memberikan Pre-test (O1) Hasil Belajar Berbasis HOTs kepada masing-masing kelompok siswa, kemudian memberikan pembelajaran dengan model pengajaran yang berbeda-beda, yaitu: Aplikasi MoLearn Terintegrasi Model BWML dan Model K 13. Akhirnya, setelah seluruh proses pembelajaran selesai dilakukan, semua kelompok siswa tersebut diberikan Post-test 
(O2) Hasil Belajar Berbasis HOTs dengan materi dan masalah yang sama sebagaimana pada Pre-test.

Analisis data menggunakan Cohen's Kappa, single measure interrater coeficient correlation $\left(r_{\alpha}\right)$, Cronbach's alpha $(\alpha)$, perhitungan gain ternormalisasi ( $n$-gain), dan deskriptif kuantitatif berupa persentase angket respon siswa. $n$-gain diperoleh dengan rumus: (nilai post tes - nilai pre tes) / (nilai maksimum - nilai pre tes), dengan kriteria dalam Table 1.

Tabel 1. Kriteria n-gain (Hake, 1999)

\begin{tabular}{ll}
\hline Skor $\mathbf{n}$-gain & Kategori \\
\hline $\mathrm{g}>0,7$ & Tinggi \\
$0,3 \leq \mathrm{g} \leq 0,7$ & Sedang \\
$\mathrm{g}<0,3$ & rendah \\
\hline
\end{tabular}

\section{HASIL DAN PEMBAHASAN Model BWML}

Pengembangan model BWML mengadaptasi desain penelitian pengembangan model Wademan. Hasil yang diperoleh dari studi literatur dan studi pendahuluan digunakan sebagai bahan untuk mengembangkan model BWML. Hasil pengembangan ini kemudian dilakukan validasi kepada 3 pakar. Intrumen penilaian kualitas model BWML diisi oleh ketiga pakar untuk mereview dan menilai kualitas model BWML (Tabel 1). Hasil penilaian ini untuk mendapatkan data validitas konten dan kostruk model BWML.

Tabel 2. Hasil analisis penilaian kualitas Model BWML

\begin{tabular}{lccccc}
\multicolumn{1}{c}{ Component } & \multicolumn{3}{c}{ Validity and Reliability of BWML Model } \\
\hline \multicolumn{1}{c}{ Content Validity } & $\begin{array}{c}\text { Validity } \\
\text { Score }\end{array}$ & $\mathbf{r}_{\alpha}$ & Validity & $\alpha$ & Reliability \\
\hline 1. Kebutuhan Pengembangan Model & 3.87 & & & & \\
$\quad \begin{array}{l}\text { Pembelajaran BWML } \\
\text { 2. State of the Art of Model BWML }\end{array}$ & 3.50 & 0.25 & Valid & 0.81 & Reliable \\
3. Kerangka Berpikir Terbentuknya Model & 3.83 & & & & \\
$\quad \begin{array}{l}\text { Pembelajaran BWML } \\
\text { 4. Deskripsi Model Pembelajaran BWML }\end{array}$ & 3.67 & & & & \\
\hline Construct Validity & & & & & \\
\hline 1. Konsistensi pengembangan Model & 4.00 & & & & \\
$\quad \begin{array}{l}\text { Pembelajaran BWML } \\
\text { 2. Kerangka berpikir terentuknya Model }\end{array}$ & 3.56 & 0.20 & Valid & \multirow{2}{*}{0.75} & Reliable \\
Pembelajaran BWML & & & & \\
3. Deskripsi Pembelajaran Model BWML & 3.67 & & & &
\end{tabular}

Tabel 2 menunjukkan bahwa validitas konten dan keandalan Model BWML meliputi: (1) Kebutuhan pengembangan model BWML, (2) State of the Art of Model BWML, (3) Kerangka berpikir terbentuknya model BWML, dan (4) Deskripsi model pembelajaran BWML memiliki skor validasi rata-rata $3.87,3.50,3.83$, dan 3.67 dengan kriteria valid dimana $\mathrm{r} \alpha=0.25$ dan lebih besar dari $r$ tabel. Dengan demikian, setiap komponen dinyatakan valid. Sedangkan untuk reliabilitas masing-masing komponen dengan nilai $\alpha=0.81$, sehingga masing-masing komponen dinyatakan reliabel.

Tabel 2 juga menunjukkan bahwa validitas konstruk dan reliabilitas Model BWML meliputi: (1) Konsistensi pengembangan Model Pembelajaran BWML, (2) Kerangka berpikir terbentuknya Model Pembelajaran BWML, dan (3) Deskripsi Pembelajaran Model BWML memiliki skor validasi rata-rata 4.00, 3.56, dan 3.67 dengan kriteria valid dan ra 0.20 lebih besar dari $r$ tabel, sehingga setiap komponen dinyatakan valid. Sedangkan untuk keandalan masing-masing komponen dalam hal nilai $\alpha$, semuanya berada pada nilai 0.75 , sehingga masing-masing komponen dinyatakan dapat diandalkan.

\section{Aplikasi Molearn}

Salah satu produk yang dihasilkan dalam penelitian ini berupa aplikasi pembelajaran berbasis mobile yang disebut 'MoLearn'. Aplikasi pembelajaran 'MoLearn' yang dihasilkan 
dapat dikelompokkan menjadi dua yaitu: (1) versi web dan (2) versi android. Uraian berikut ini akan dibahas masing-masing dari aplikasi tersebut.

\section{'MoLearn' versi web}

Pada 'MoLearn' versi web tampilan awal ketika kita masuk akan tampak seperti pada Gambar 2. Untuk dapat memanfaatkan aplikasi pembelajaran 'MoLearn' ini, pengguna harus login terlebih dahulu. Hal ini diperlukan untuk melakukan verifikasi agar pengguna benarbenar orang yang terdaftar, karena aplikasi ini terkait dengan sistem administrasi baik di tingkat kelas, sekolah sampai dengan dinas pendidikan Provinsi. Pada halaman login iniu pengguna harus memilih kewenangan pengguna sebagai apa, MGMP-Guru-Siswa selanjutnya memasukkan ID pengguna dan kata sandi.

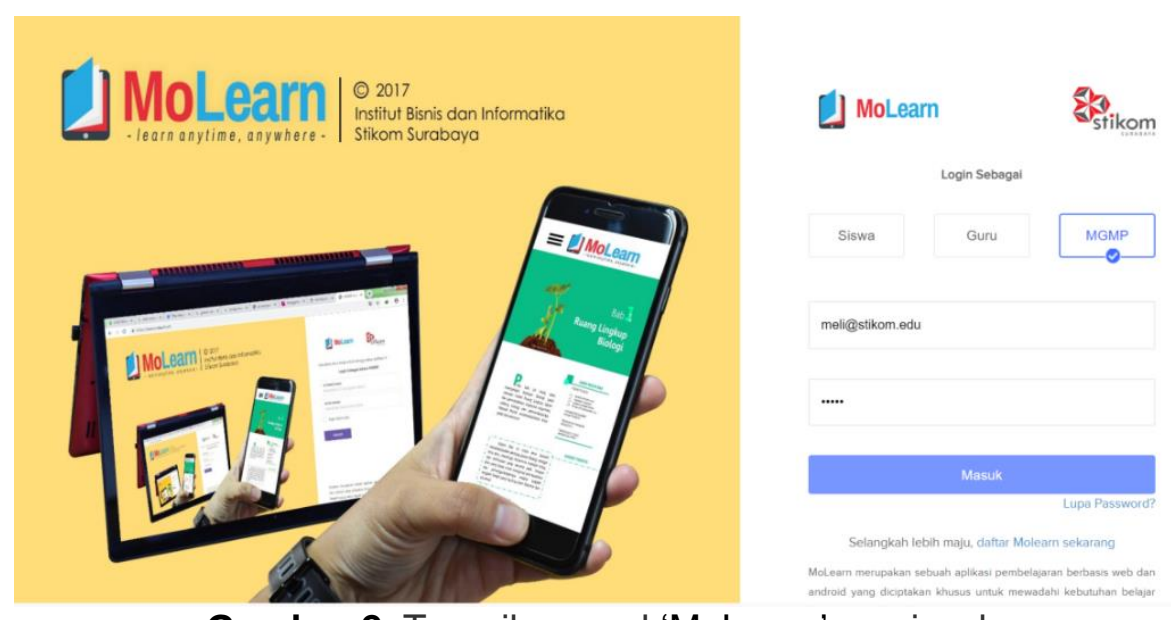

Gambar 2. Tampilan awal 'MoLearn' versi web

Pada aplikasi ini, konten yang dimuat juga mengacu pada kurikulum, oleh karena itu pada langkah awal pengisian pada aplikasi ini dimulai dari data sekolah, data siswa, data guru dan kurikulum mulai kelas X sampai kelas XII. Masing-masing pengguna memiliki kode user dan password yang dapat digunakan untuk masuk dalam aplikasi ini.

\section{'MoLearn' versi android}

Pada 'MoLearn' versi android tampilan awal ketika kita masuk akan tampak seperti pada Gambar 3. Seperti halnya pada versi web, pada versi android ini pengguna juga diminta login terlebih dahulu dengan menentukan kewenangan pengguna sebagai apa, MGMP-GuruSiswa selanjutnya memasukkan id pengguna dan kata sandi. Secara umum tampilan versi web dan versi android hapir sama, hanya saja pada versi android tidak disediakan fasilitas untuk mengisi data sekolah, guru dan siswa, konten dan beberapa data yang cukup besar karena akan menyulitkan pengguna. Tetapi untuk fasilitas lihat data dan bahan ajar serta memberikan komentar dalam tugas, penilaian dan diskusi masih bisa digunakan.

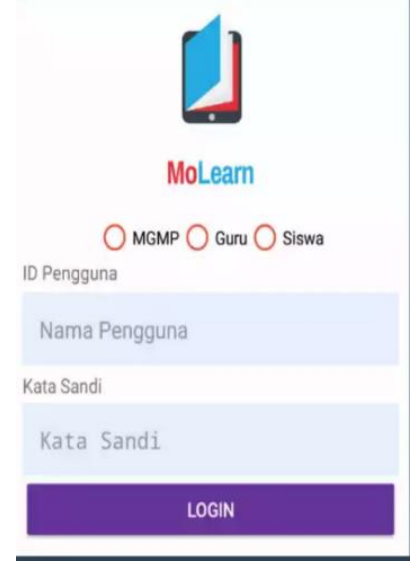

Gambar 3. Tampilan awal MoLearn versi android 
Setelah seorang pengguna diverifikasi dan dinyatakan sesuai, maka yang bersangkutan dapat menggunakan aplikasi MoLearn ini dan akan masuk pada tampilan awal memilih mata pelajaran. Setelah dipilih mata pelajaran yang diharapkan, maka akan diarahkan pada tampilan menu utama mata pelajaran yang dipilih sebagaimana pada Gambar 4.

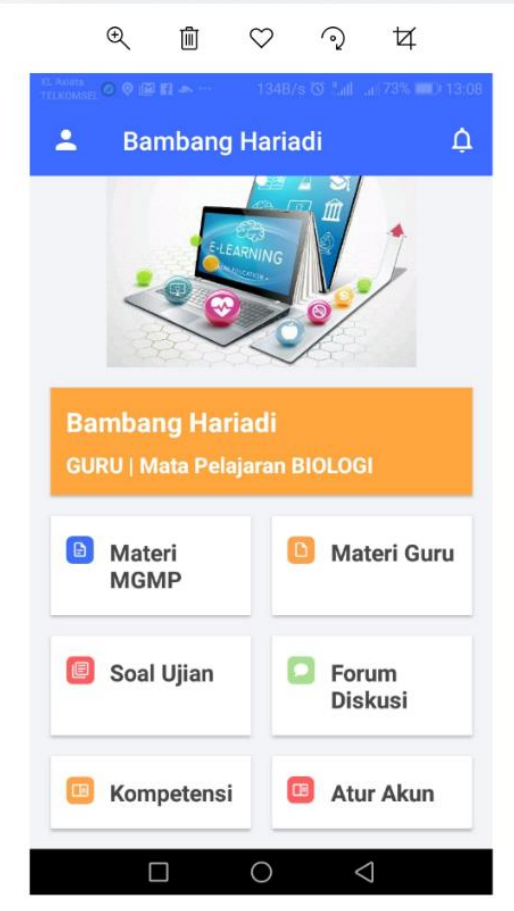

Gambar 4. Tampilan menu utama mata pelajaran MoLearn versi android

\section{Hasil Belajar Siswa}

Pada saat implemntasi model BWML menggunakan aplikasi MoLearn akan dimulai dilakukan tes awal untuk mengetahui kemampuan siswa sebelum pembelajaran. Selanjutnya, setelah dilakukan pembelajaran menggunakan aplikasi MoLearn dilakukan tes akhir dengan soal yang sama dengan tes awal. Selisih antara nilai tes akhir dengan tes awal inilah yang kemudian disebut sebagai gain yaitu peningkatan kemampuan yang diperoleh setelah dilakukan pembelajaran. Gain ini selanjutnya diperhalus dengan melakukan normalisasi nilai gain selanjutnya disebut $n$-gain yang dihitung menggunakan rumus:

n-gain $=$ [skor post-test - skor pre-test $] /[100$ - pre-test $]$

Uji coba telah dilakukan di empat kota yaitu Surabaya, Sidoarjo, Jombang dan Nganjuk dengan melibatkan 6 SMA sebagai pilot. Hasil rerata pre-test dan post-test serta perhitungan n-gain hasil implementasi pembelajaran model BWML dapat dilihat dalam Tabel 3 dan Tabel 4.

Tabel 3. Rerata Skor Pre-test dan Post-test pada Sekolah Uji Coba

\begin{tabular}{|c|c|c|c|c|c|c|c|c|c|c|c|}
\hline \multicolumn{12}{|c|}{ Kelompok } \\
\hline \multicolumn{2}{|c|}{ Pilot-1 } & \multicolumn{2}{|c|}{ Pilot-2 } & \multicolumn{2}{|c|}{ Pilot-3 } & \multicolumn{2}{|c|}{ Pilot-4 } & \multicolumn{2}{|c|}{ Pilot-5 } & \multicolumn{2}{|c|}{ Pilot-6 } \\
\hline $\begin{array}{c}\text { Pre - } \\
\text { test }\end{array}$ & $\begin{array}{c}\text { Post- } \\
\text { test }\end{array}$ & $\begin{array}{c}\text { Pre - } \\
\text { test }\end{array}$ & $\begin{array}{c}\text { Post- } \\
\text { test }\end{array}$ & $\begin{array}{c}\text { Pre - } \\
\text { test }\end{array}$ & $\begin{array}{c}\text { Post- } \\
\text { test }\end{array}$ & $\begin{array}{c}\text { Pre - } \\
\text { test }\end{array}$ & $\begin{array}{c}\text { Post- } \\
\text { test }\end{array}$ & $\begin{array}{c}\text { Pre - } \\
\text { test }\end{array}$ & $\begin{array}{c}\text { Post- } \\
\text { test }\end{array}$ & $\begin{array}{c}\text { Pre - } \\
\text { test }\end{array}$ & $\begin{array}{c}\text { Post- } \\
\text { test }\end{array}$ \\
\hline 24,37 & 69,29 & 19,25 & 74,09 & 69,17 & 85,08 & 25,97 & 76,97 & 29,06 & 50,06 & 13,33 & 37,83 \\
\hline
\end{tabular}

Tabel 3 menunjukkan bahwa pada setiap SMA yang dilakukan uji coba terjadi peningkatan rata-rata nilai post-test. Ini berarti setelah dilakukan pembelajaran dengan model BWML terjadi pemahaman terhadap materi yang diajarkan dan ada peningkatan nilai posttest jika dibandingkan dengan nilai pre-test. Selanjutnya untuk memperhalus makna 
peningkatan rata-rata nilai ini dilakukan penghitungan n-gain yaitu gain yang distandarkan. Hasil rata-rata n-gain dari keenam SMA uji coba sebagaimana pada Tabel 4.

Tabel 4. Rerata n-gain pada Sekolah Uji Coba

\begin{tabular}{ccccccc}
\hline Kelompok & Pilot-1 & Pilot-2 & Pilot-3 & Pilot-4 & Pilot-5 & Pilot-6 \\
\hline$\sum$ Sampel : $N$ & 35 & 36 & 36 & 33 & 35 & 30 \\
Rerata n-gain & 0,60 & 0,67 & 0,41 & 0,70 & 0,31 & 0,28 \\
\hline
\end{tabular}

Tabel 4 menunjukkan bahwa rata-rata n-gain dari keenam SMA uji coba bervariasi. Namun jika di rata-rata n-gain keenam SMA tersebut diperoleh angka 0,46 dengan kategori sedang (Hake, 1999). Dengan demikian, dapat dikatakan bahwa terjadi peningkatan hasil belajar dengan nilai n-gain berkategori sedang. Hal ini berarti bahwa pembelajaran dengan model BWML menggunakan aplikasi MoLearn dapat meningkatkan hasil belajar dengan kategori sedang. Hasil ujicoba BWML dengan aplikasi MoLearn juga menunjukkan 83\% menyatakan senang menggunakan MoLearn. Di samping itu, hasil respon siswa menunjukkan bahwa (1) siswa mendapat bantuan guru 83\%; (2) mudah dalam pengoperasian $71 \%$; dan (3) keterbaruan $81 \%$, menunjukkan model ini praktis digunakan dalam pembelajaran.

\section{KESIMPULAN}

Dari uraian pembahasan di atas, maka dapat disimpulkan hasil dari penelitian ini adalah model Blended Web Mobile Learning (BWML) dengan aplikasi MoLearn telah memenuhi syarat validitas dan reliabilitas dari penilaian ahli; (2) aplikasi pembelajaran MoLearn versi web dan versi android telah memenuhi syarat user friendly dan dapat digunakan untuk pembelajaran dengan pendekatan blended learning dengan model BWML bagi siswa SMA; dan (3) Hasil uji coba pada sekolah pilot menunjukkan bahwa terjadi peningkatan hasil belajar berbasis Higher Order Thinking Skills (HOTS) dengan nilai n-gain berkategori sedang.

\section{REKOMENDASI}

Penelitian lanjutan dapat dilakukan untuk: (1) menguji model BWML pada skala lebih luas, (2) pengembangan aplikasi yang digunakan untuk mata pelajaran lainnya, (3) subjek penelitian bisa diubah pada level SD, SMP, dan PT.

\section{UCAPAN TERIMAKASIH}

Ucapan terima kasih kami sampaikan kepada Direktur Utama Lembaga Pengelola Dana Pendidikan Kementerian Keuangan Republik Indonesia yang telah memberikan pendanaan Riset Inovatif Produktif (RISPRO) sesuai surat perjanjian pendanaan nomor: PRJ74/LPDP/2020 tanggal 18 September 2020. Ucapan terima kasih juga disampaikan kepada Rektor beserta jajaran pimpinan Universitas Dinamika yang telah memberikan kesempatan dan dukungan kepada peneliti untuk melakukan aktivitas penelitian ini sampai tuntas.

\section{DAFTAR PUSTAKA}

Arizaga, M. P. G.-, Bahar, A. K., Maker, C. J., Zimmerman, R., \& Pease, R. (2016). How Does Science Learning Occur in the Classroom? Students' Perceptions of Science Instruction During the Implementation of the REAPS Model. EURASIA Journal of Mathematics, Science and Technology Education, 12(3). https://doi.org/10.12973/eurasia.2016.1209a

Atsani, L. G. M. Z. (2020). Transformasi media pembelajaran pada masa pandemi covid-19. al-Hikmah : Jurnal Studi Islam, 1(1), 82-93.

Benade, L. (2018). BEING A TEACHER IN THE 21ST CENTURY: A critical new zealand research study. SPRINGER Verlag, SINGAPOR.

Caesar, M. I. M., Jawawi, R., Matzin, R., Shahrill, M., Jaidin, J. H., \& Mundia, L. (2016). The Benefits of Adopting a Problem-Based Learning Approach on Students' Learning Developments in Secondary Geography Lessons. International Education Studies, 9(2), 51. https://doi.org/10.5539/ies.v9n2p51

Chakravarthi, S., \& Haleagrahara, N. (2010). Implementation of PBL curriculum involving multiple disciplines in undergraduate medical education programme. International Education Studies, 3(1), p165. https://doi.org/10.5539/ies.v3n1p165 
Fraenkel, J. R., Wallen, N. E., \& Hyun, H. H. (2012). How to design and evaluate research in education (8th ed). McGraw-Hill Humanities/Social Sciences/Languages.

Hake, R. R. (1999). Analyzing Change/Gain Scores*. 4.

Hariadi, B. (2015). Web-based cooperative learning, learning styles, and student's learning outcomes. Jurnal Cakrawala Pendidikan, 2(2). https://doi.org/10.21831/cp.v2i2.4821

Hariadi, B., Sunarto, M. J. D., \& Sudarmaningtyas, P. (2016). Development of Web-Based Learning Application for Generation Z. International Journal of Evaluation and Research in Education (IJERE), 5(1), 60. https://doi.org/10.11591/ijere.v5i1.4523

Hariadi, B., \& Wurijanto, T. (2016). Influence of Web Based Cooperative Learning Strategy and Achiever Motivation on Student Study Outcome. International Journal of Evaluation and Research in Education (IJERE), 5(3), 189. https://doi.org/10.11591/ijere.v5i3.4538

Jatmiko, B., Prahani, B. K., Munasir, M., Imam Supardi, Z. A., Wicaksono, I., Erlina, N., Pandiangan, P., Althaf, R., \& Zainuddin, Z. (2018). The comparison of or-ipa teaching model and problem based learning model effectiveness to improve critical thinking skills of pre-service physics teachers. Journal of Baltic Science Education, 17(2), 300319. https://doi.org/10.33225/jbse/18.17.300

Nasrullah, R., Aditya, W., Satya, T. I., Nento, M. N., Hanifah, N., Miftahussururi, M., \& Akbari, Q. S. (2017). Materi pendukung literasi digital (L. A. Mayani, Ed.). Direktorat Jenderal Pendidikan Dasar dan Menengah. http://repositori.kemdikbud.go.id/11635/

Nieveen, N. (1999). Prototyping to Reach Product Quality. Dalam J. van den Akker, R. M. Branch, K. Gustafson, N. Nieveen, \& T. Plomp (Ed.), Design Approaches and Tools in Education and Training (hlm. 125-135). Springer Netherlands. https://doi.org/10.1007/978-94-011-4255-7_10

Pandiangan, P., Sanjaya, I. G. M., \& Jatmiko, B. (2017). The validity and effectiveness of physics independent learning model to improve physics problem solving and selfdirected learning skills of students in open and distance education systems. Journal of Baltic Science Education, 16(5), 651-665. https://doi.org/10.33225/jbse/17.16.651

Plomp, T. (2013). Preparing education for the information society: Implementation challenges. International Journal of Social Media and Interactive Learning Environments, 1(3), 224. https://doi.org/10.1504/IJSMILE.2013.055752

Prahani, B. K., Nur, M., Yuanita, L., \& Limatahu, I. (2017). Validitas model pembelajaran group science learning; pembelajaran inovatif di Indonesia. Vidya Karya, 31(1). https://doi.org/10.20527/jvk.v31i1.3976

Prahani, B. K., Suprapto, N., Suliyanah, Lestari, N. A., Jauhariyah, M. N. R., Admoko, S., \& Wahyuni, S. (2018). The effectiveness of collaborative problem based physics learning (CPBPL) model to improve student's self-confidence on physics learning. Journal of Physics: Conference Series, 997, 012008. https://doi.org/10.1088/1742$6596 / 997 / 1 / 012008$

Sern, L. C., Salleh, K. M., Sulaiman, N. lisa, Mohamad, M. M., \& Yunos, J. M. (2015). Comparison of Example-based Learning and Problem-based Learning in Engineering Domain. Universal Journal of Educational Research, 3(1), 39-45. https://doi.org/10.13189/ujer.2015.030106

Sunarti, T., Wasis, Madlazim, Suyidno, \& Prahani, B. K. (2018). The effectiveness of CPI model to improve positive attitude toward science (PATS) for pre-service physics teacher. Journal of Physics: Conference Series, 997, 012013. https://doi.org/10.1088/1742-6596/997/1/012013

Sunarto, M. J. D. (2021). The Development of Flipped Learning Model Based on MyBrilian to Support Planned Online Learning. Jurnal Penelitian dan Pengkajian IImu Pendidikan: e-Saintika, 5(1), 27. https://doi.org/10.36312/e-saintika.v5i1.379

Sunarto, M. J. D., Hariadi, B., Amelia, T., \& Sagirani, T. (2017). Initialization requirement in developing of mobile learning 'Molearn' for biology students using inquiry-based learning. 2017 International Conference on Applied System Innovation (ICASI), 18651867. https://doi.org/10.1109/ICASI.2017.7988310

Suyidno, S., Nur, M., Yuanita, L., Prahani, B. K., \& Jatmiko, B. (2018). Effectiveness of creative responsibility based teaching (crbt) model on basic physics learning to increase 
student's scientific creativity and responsibility. Journal of Baltic Science Education, 17(1), 136-151. https://doi.org/10.33225/jbse/18.17.136

Umam, K. (2013). Penerapan media digital dalam pembelajaran apresiasi batik kelas x sma negeri 1 Blega. Jurnal Seni Rupa, 1(1), Article 1. https://jurnalmahasiswa.unesa.ac.id/index.php/va/article/view/9788

Wicaksono, I., Wasis, W., \& Madlazim, M. (2017). The effectiveness of virtual science teaching model (vs-tm) to improve student's scientific creativity and concept mastery on senior high school physics subject. Journal of Baltic Science Education, 16(4), 549-561. https://doi.org/10.33225/jbse/17.16.549 